\section{A viable, cutting-edge alternative}

Quality removable partial dentures created from Ultaire AKP are a viable, cutting-edge alternative to traditional metal or flexible devices.

Ultaire AKP is a lightweight, biocompatible, material specifically developed for advanced digital manufacturing processes.

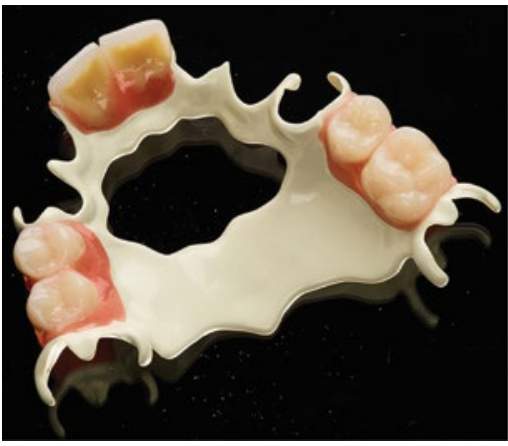

With bone-like properties, Ultaire AKP offers comfortable retention with a natural feel and its creators, Solvay Dental 360 are happy to visit dental practices to explain the benefits of using metal-free, polymer based frameworks.

\section{Polished with diamonds}

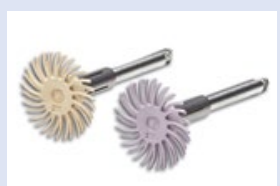

The aesthetics of a restoration are so dependent on the equipment you use during treatment.

This is true for every step of the journey.

Give your patients a polished finish by choosing the Sof-Lex Diamond polishing system from $3 \mathrm{M}$ Oral Care.

Suitable for sterilisation and reuse, the Sof-Lex Diamond polishing system helps
A well-fitting denture can help to maintain a youthful appearance; aid function and become a part of your patient's life. So contact Solvay 360 today to find out more.

To book a Solvay Dental 360 Professional Lunch and Learn or to find more information about Ultaire AKP and Dentivera milling discs, visit www.solvaydental360.com.

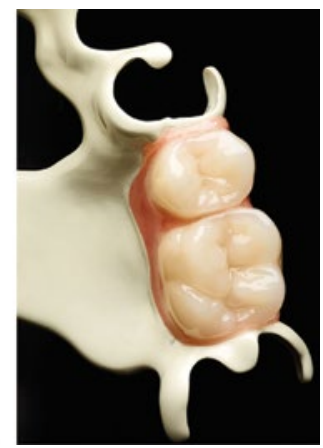

\section{Built for your needs}

As a leading manufacturer of decontamination equipment, $\mathrm{W} \& \mathrm{H}$ is excited to offer clinicians the new Teon and Teon+ thermal washer disinfectors.

With their easy-to-use displays, high capacity chambers and dedicated programmes, these systems ensure efficient but gentle cleaning and disinfection of all your instruments. This reduces the risk of cross contamination and enables you to maintain an organised decontamination room.

Equipped with various different compartments for optimal loading, the Teon+ also offers full traceability to meet current and future regulatory requirements. What's more, its patented active air-drying system sets new standards with regard to quality and performance.

Get in touch with W\&H to find out more. Visit www.wh.com/en_uk, call 01727874990 or email office.uk@ wh.com.

to create a natural gloss in a fast, two-step procedure. Additionally, the system can easily help clinicians achieve the aesthetics that their patients expect, meaning there will be smiles all round!

To find out more about the Sof-Lex Diamond polishing system, contact 3M Oral Care.

Call 0800626578 or visit www.3m. co.uk/Dental. 3M and Sof-Lex are trademarks of the $3 \mathrm{M}$ Company.

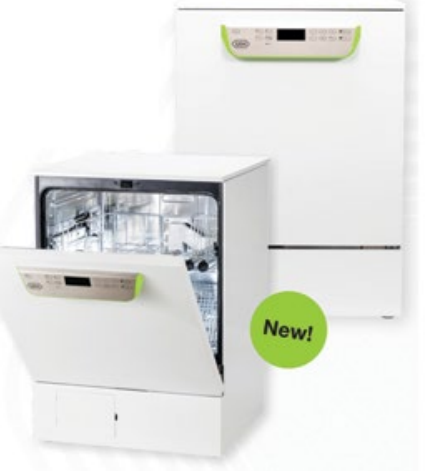

\title{
Meet patients' expectations
}

Are you looking to offer dental implant restorations? If so, then ensure you gain the necessary skills and experience required to carry out treatment competently by joining Ten Dental Facial's dedicated Implant Restoration Course (IRC).

This professional five-module course is taught by renowned implantologists, Drs Nikhil Sisodia and Martin Wanendeya (pictured).

Through a series of interactive lectures, seminars, and hands-on workshops, practitioners can explore in depth the various elements involved with restoring implants. This ensures aspiring clinicians are fully

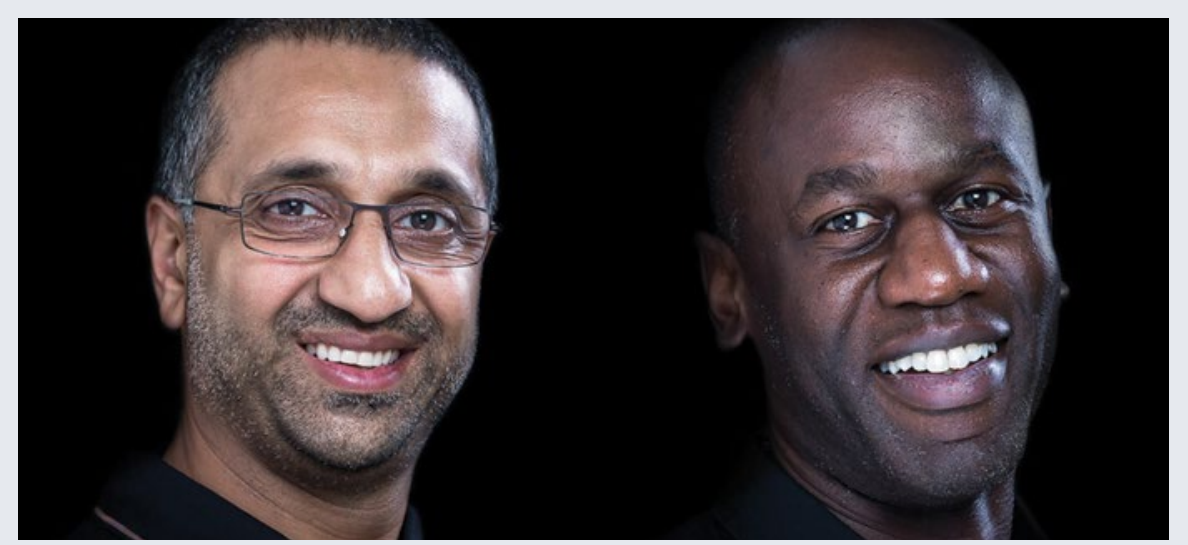

equipped to deliver safe, effective results for patients looking to restore the health and appearance of their smile.

For more information about Ten Dental
Facial's IRC, visit Facebook/Implant Restoration Course-IRC, email: office@ tendental.com, visit www.implant-restoration.com or call 02076227610 . 